\title{
Magnetic Cellulose Beads as Support for Enzyme Immobilization Using Polyelectrolytes through Electrostatic Adsorption
}

Rina $\mathrm{Wu} *$ and Le Liu

\begin{abstract}
Pectinase was immobilized on magnetic regenerated cellulose microspheres using cationic polyacrylamide (CPAM) or polyethyleneimine (PEI) via electrostatic adsorption. PEl-immobilized enzyme (PEI-EMCB) had higher activity $(2711 \mathrm{U} / \mathrm{g})$ than CPAM-immobilized enzyme (CPAMEMCB). The time course of PEl-immobilized enzyme catalytic reaction was similar to the free form. $\mathrm{PEI}$-EMCB reached its maximal activity at $\mathrm{pH}$ 4.8, while the optimal $\mathrm{pH}$ for CPAM-EMCB was the same with the free form (4.4). CPAM3-EMCB was most tolerant to $\mathrm{pH}$ variation, which can be possibly ascribed to the high molecular weight of CPAM3. After immobilization, the optimum temperature for the enzyme declined from 45 ${ }^{\circ} \mathrm{C}$ to different degrees. PEI-EMCB exhibited good storage stability with $67 \%$ of the initial activity maintained after 7 days and with moderate reusability. The magnetic properties of the regenerated cellulose beads provided convenience for the immobilized enzyme to be used and recycled. The results indicate a potential route for utilization of cellulose as enzyme support via a simple method.
\end{abstract}

Keywords: Cellulose; Magnetic; Adsorption; Polyelectrolyte; Immobilized enzyme

Contact information: Tianjin Key Laboratory of Pulp \& Paper, Tianjin University of Science \& Technology, Tianjin 300457, China; *Corresponding author: wu.rn@tust.edu.cn

\section{INTRODUCTION}

As the consumption of non-renewable resources and environmental pollution accompanied by the exploitation of petroleum-based polymers pose an increasing threat, it is of great importance to develop environmentally friendly processes and materials from renewable resources. Cellulose has drawn particular attention among natural polymers due to its merits, including its abundance, renewability, and biodegradability. Moreover, cellulosic materials are generally nontoxic, stable, and inexpensive (Wang et al. 2016). Cellulose in bead form has found application in chromatography, water treatment, drug delivery, protein immobilization, etc. (Gericke et al. 2013; Coombs OBrien et al. 2017).

Enzymes are increasingly exploited in the area of biocatalysts, pharmaceutics, biosensors, and the food industry due to their effectiveness, high selectivity, biodegradability, and mild reaction conditions (Choi et al. 2015). Despite its advantages, the application of the enzymatic method is often limited due to lack of operational stability and recyclability. To overcome these drawbacks, enzymes can be immobilized on a carrier for reuse, convenient separation, and enhanced performance (Bolivar et al. 2016). Among the immobilization methods, adsorption is a simple and convenient method with low cost. Moreover, the active centers of the enzyme stay native and the support matrices can be recycled because this approach does not involve chemical modification (Liu et al. 2018). Immobilization through electrostatic interaction using polyelectrolyte might be a useful 
methodology considering its simplicity for industrial application (Guzmán et al. 2017). Polyethyleneimine (PEI) and cationic polyacrylamide (CPAM) are among the most commonly used polyelectrolytes in many industrial processes, such as papermaking and wastewater treatment, due to their high efficiency and low cost (Fuente et al. 2005; Wang et al. 2014). PEI has been reported to be effective in stabilizing enzymes such as lipases (Santos et al. 2014; Zaak et al. 2017), $\beta$-galactosidase (Mateo et al. 2000), glutamate dehydrogenase, formate dehydrogenase (Bolivar et al. 2009), and nitrilases (Mateo et al. 2006). CPAM has also been utilized in enzyme immobilization (Rehman et al. 2016) and found to improve enzyme performance (Wang et al. 2015).

In the authors' previous study, regenerated cellulose beads were prepared via a simple method, and the cellulose beads obtained exhibited good property as an enzyme carrier. Moreover, pectinase was immobilized on regenerated cellulose beads through physical adsorption without any bridging agent, and the results have shown that the bound enzyme could be prospectively employed for wastewater treatment in the papermaking industry. In the present study, enzyme was immobilized on regenerated cellulose microspheres using CPAM or PEI via electrostatic adsorption to obtain a bound enzyme with higher activity and stability. The properties of the immobilized pectinase were characterized. Apart from that, magnetite $\left(\mathrm{Fe}_{3} \mathrm{O}_{4}\right)$ was incorporated into cellulose beads for the fixed enzyme to be conveniently separated from the reaction mixture using a magnet.

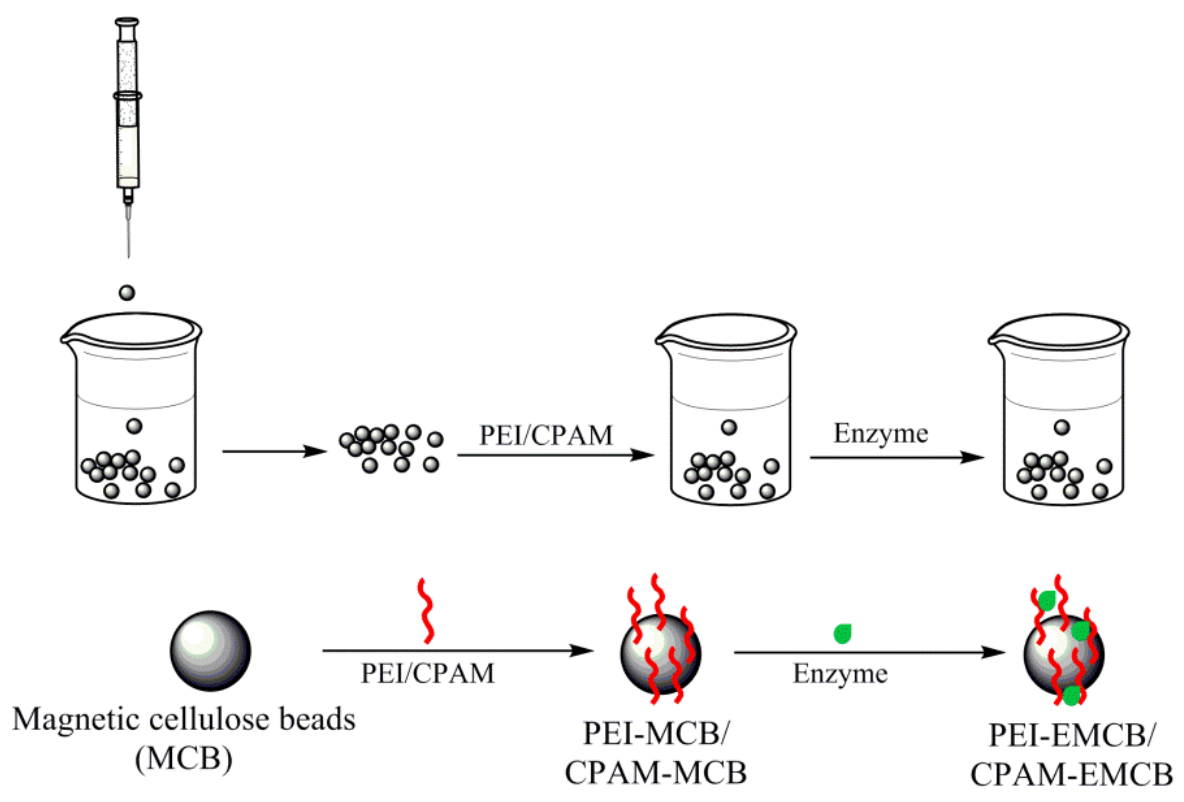

Scheme 1. Scheme of the experiment process

\section{EXPERIMENTAL}

\section{Materials}

Microcrystalline cellulose was purchased from Sinopharm Chemical Reagent Co., Ltd. (Tianjin, China). $\mathrm{Fe}_{3} \mathrm{O}_{4}$ nanoparticles were purchased from Shanghai Macklin Biochemical Co., Ltd. (Shanghai, China). Commercially available pectinase Novozyme 863 was supplied by Novozymes (Tianjin, China). Pectin from citrus peel and polyethyleneimine (PEI, MW 70 000) as 50\% (w/v) were purchased from J\&K Scientific 
Ltd. (Beijing, China). Cationic polyacrylamide (CPAM) was provided by Nuoer Chemical (Dongying, China), and its information is listed in Table 1. All other commercially available chemicals were purchased from local markets and were of analytical grade.

Table 1. Enzymatic Activity of Immobilized Enzymes Using Different CPAM Samples

\begin{tabular}{|c|c|c|c|c|}
\hline CPAM Samples & $\begin{array}{c}\text { Molecular Weight } \\
\left(\times 10^{4}\right)^{\mathrm{a}}\end{array}$ & $\begin{array}{c}\text { Charge Density } \\
(\mathrm{mmol} / \mathrm{g})^{\mathrm{b}}\end{array}$ & $\begin{array}{c}\text { Enzymatic Activity } \\
(\mathrm{U} / \mathrm{g})\end{array}$ & $\begin{array}{c}\text { Activity recovery } \\
(\%)\end{array}$ \\
\hline CPAM1 & 317 & 0.75 & 1300 & 1.43 \\
\hline CPAM2 & 550 & 1.26 & 237 & 0.26 \\
\hline CPAM3 & 559 & 0.85 & 1699 & 1.87 \\
\hline CPAM4 & 790 & 1.24 & 776 & 0.86 \\
\hline
\end{tabular}

aMeasured with viscosity method.

${ }^{b}$ Measured using streaming current detector.

\section{Methods}

Preparation of magnetic cellulose beads

A $3 \mathrm{wt} \%$ cellulose solution was prepared (Wu et al. 2016). A total of $100 \mathrm{~g}$ of cellulose solution was placed in an $85{ }^{\circ} \mathrm{C}$ bath, and $0.6 \mathrm{~g} \mathrm{Fe}_{3} \mathrm{O}_{4}$ nanoparticles were added to the solution while stirring. The mixture was stirred at $800 \mathrm{rpm}$ for $20 \mathrm{~min}$ and cooled to $25{ }^{\circ} \mathrm{C}$. Subsequently, the mixture was added dropwise to ethanol to obtain magnetic regenerated cellulose beads (MCB) instantaneously. The beads were washed thoroughly with ethanol and then with deionized water. The morphology of the magnetic regenerated cellulose beads was observed using scanning electron microscopy (JSM-IT300LV; JEOL, Tokyo, Japan). Magnetic measurements of the MCB were performed using vibration sample magnetometry (Squid-VSM; Quantum Design, San Diego, CA, USA).

\section{Immobilization of pectinase on magnetic cellulose beads}

A total of $10 \mathrm{~g}$ of wet MCBs were immersed in $100 \mathrm{~mL} 0.01 \%(\mathrm{w} / \mathrm{v})$ PEI or CPAM aqueous solution. The mixture was shaken for $30 \mathrm{~min}$ at $25^{\circ} \mathrm{C}$. After adsorption, MCBs were separated from the solution by magnetic field and washed with deionized water to remove excess PEI/CPAM. Then, the beads were immersed in $100 \mathrm{~mL}$ of $0.25 \%(\mathrm{v} / \mathrm{v})$ pectinase solution for adsorption for $30 \mathrm{~min}$ at $25^{\circ} \mathrm{C}$, separated, and washed. The resultant immobilized pectinase on magnetic cellulose beads (PEI-EMCB/CPAM-EMCB) was stored at $4{ }^{\circ} \mathrm{C}$ between uses.

Assay of enzyme activity

The activity and $\mathrm{pH} /$ thermal stability of the free/immobilized pectinase was assayed as previously described (Wu et al. 2016). Briefly, the enzymatic activity was determined using pectin as the substrate via the dinitrosalicylic acid (DNS) method, and one unit was defined as the amount of enzyme necessary to release $1 \mu \mathrm{g}$ of galacturonic acid per min. Activity recovery (\%) describing the efficiency of the immobilization process was determined by dividing the total observed activity of the immobilized enzyme by the total activity of the free enzyme used (Sheldon and van Pelt 2013). 


\section{Catalytic Properties of the Free and Immobilized Enzyme}

The enzymatic reaction course was monitored through batch reaction; $0.1 \mathrm{~mL}$ of $0.25 \%(\mathrm{v} / \mathrm{v})$ free pectinase or $0.2 \mathrm{~g}$ of the immobilized pectinase was added to $2 \mathrm{~mL}$ pectin. The concentration of the generated galacturonic acid was measured using the DNS method for different reaction duration. Effects of $\mathrm{pH}$ and temperature on the activities of free/immobilized enzyme were assessed by measuring the activities in different $\mathrm{pH}$ values or at different temperatures.

The apparent kinetic parameters (maximum reaction rate $V_{\mathrm{m}}$ and Michaelis-Menten constant value $K_{\mathrm{m}}$ ) were estimated using Lineweaver-Burk plot. The initial rate of the reaction was measured for free $(0.1 \mathrm{~mL})$ and immobilized $(0.2 \mathrm{~g})$ enzymes using pectin solution $(2 \mathrm{~mL})$ of different concentrations. The reaction was performed at $35^{\circ} \mathrm{C}$.

\section{Storage Stability and Reusability of Immobilized Enzyme}

The immobilized enzyme was stored at $4{ }^{\circ} \mathrm{C}$, and the activity was measured for different storage periods to assess the storage stability of immobilized pectinase. The reusability of the immobilized enzyme was evaluated by assaying the activity of the enzyme for repeated uses. The immobilized enzyme on cellulose beads was collected using a magnet after reaction, rinsed by deionized water, and reused for catalysis using a fresh pectin solution.

\section{RESULTS AND DISCUSSION}

\section{Structure of the Magnetic Regenerated Cellulose Beads}

As the cellulose solution with $\mathrm{Fe}_{3} \mathrm{O}_{4}$ nanoparticles was dripped into ethanol, spherical magnetic regenerated cellulose beads formed instantaneously. The spheres were formed by hydrogen bonding and possibly chain entanglement because no crosslinking agent was used (Wu et al. 2016).
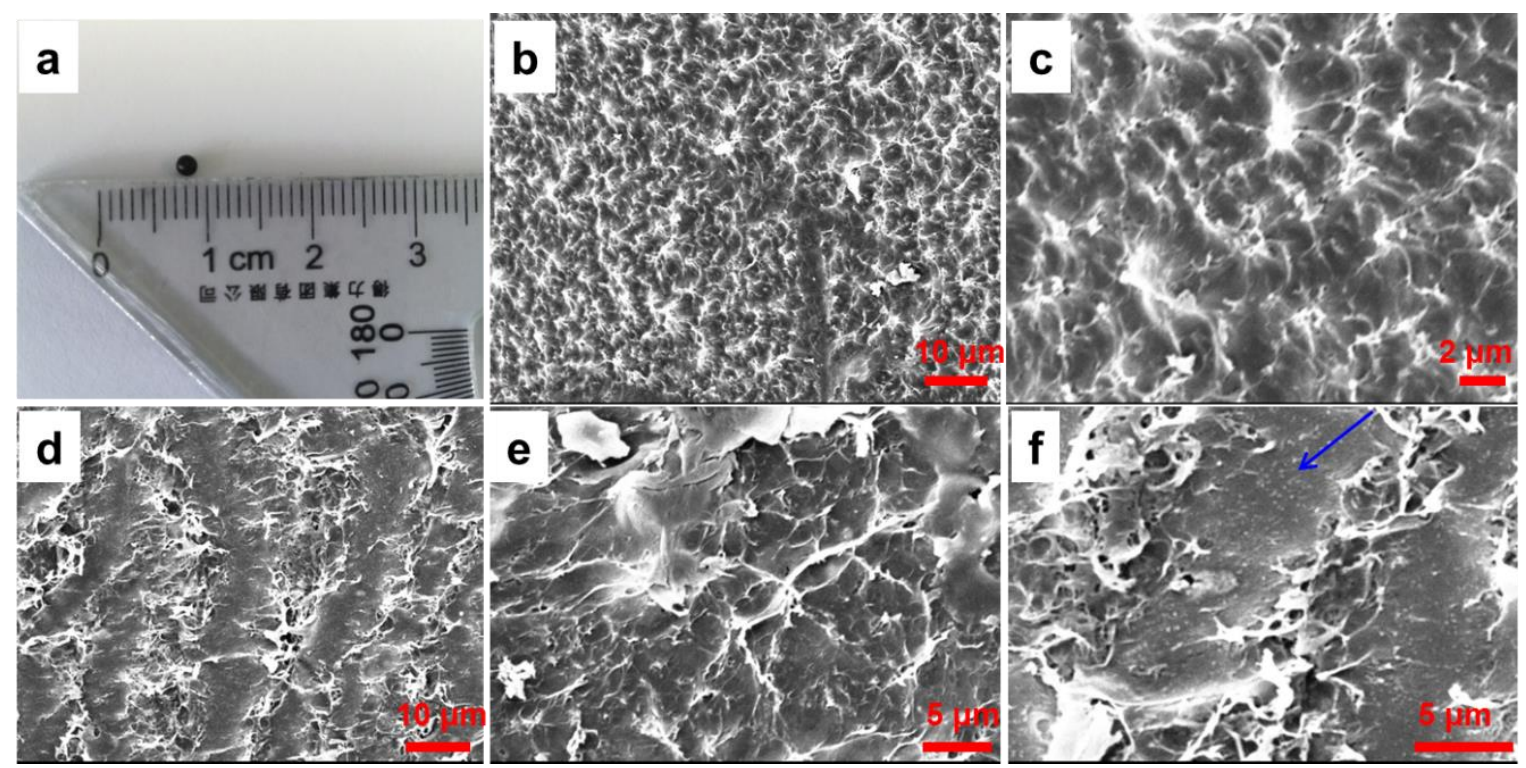

Fig. 1. Image of magnetic regenerated cellulose beads (a) and SEM images of surface (b, c) and cross-section $(d, e, f)$ of magnetic regenerated cellulose beads 
The beads exhibited good spherical shape with a diameter of approximately 1 to 2 $\mathrm{mm}$, as illustrated in Fig. 1a. It was observed from SEM that the surface of cellulose beads was not smooth. As the cellulose solution was added to ethanol, the solvent was substituted by ethanol, leading to the formation of pores on the surface of beads in solvent-rich regions and an increased roughness (Bognitzki et al. 2001). The cross-section structure of the magnetic regenerated cellulose microspheres is depicted in Figs. 1d through 1f. The porous structure penetrated the interior part of the microspheres, forming a three-dimensional network. Moreover, it could be observed that $\mathrm{Fe}_{3} \mathrm{O}_{4}$ particles were doped in the cellulose beads, as shown by the arrow in Fig 1f.

\section{Immobilization of Pectinase Using Different Polyelectrolytes}

Different CPAM samples were used as bridging agent for enzyme immobilization, and the activity of the bound enzymes is listed in Table 1. Among all the immobilized enzymes, the one immobilized using CPAM3 exhibited the highest catalytic activity. When immobilized with CPAM of high charge density in this study (CPAM2 and CPAM4), the pectinase obtained had very low activity. The high charge density of CPAM led more enzyme molecules to be fixed on the support through electrostatic adsorption. This might be disadvantageous for enzymatic activity, since a negative reaction between the bound enzyme molecules might occur, thus undermining the catalytic activity (Fernandez-Lopez et al. 2017). Moreover, an undesirable polyelectrolyte complex between CPAM and pectinase, which might be disadvantageous for the properties of the enzyme, is likely to form (Guzmán et al. 2017). Compared with CPAM1, CPAM3 had similar charge density and larger molecular weight. The large molecule might prevent the polymer from diffusing into the interior and staying on the surface of the carrier, which is beneficial for the adsorption of enzyme. However, the activity recovery during the immobilization process was low in all circumstances, as listed in Table 1. The PEI was also used to immobilize the enzyme and the obtained enzyme exhibited activity of $4615 \mathrm{U} / \mathrm{g}$ with an activity recovery of 5.09\%, which was much higher than CPAM-immobilized enzymes. The high activity of PEI-immobilized enzyme might be achieved by the positive effects of PEI-enzyme interactions (Santos et al. 2014). In the subsequent study, PEI, CPAM1, and CPAM3 were utilized for enzyme immobilization to assess the enzyme properties.

\section{Catalytic Properties of the Enzymes}

During the enzymatic reaction course, galacturonic acid (GA) was generated from pectin, and the change of GA concentration as a function of time was monitored as illustrated in Fig. 2. It was found that the catalytic reaction course of CPAM1-EMCB and CPAM3-EMCB was similar. In contrast, the concentration of galacturonic acid in PEIimmobilized enzyme catalyzed reaction was much higher, and the catalytic reaction course for PEI-EMCB was closer to its free counterpart. It could be inferred from the slope of the curve that the reaction rate in the PEI-EMCB reaction was comparable with the free form, which was remarkably faster than CPAM immobilized enzymes. After 30 min, the amount of generated GA in PEI-EMCB catalyzed reaction was approximately $0.45 \mathrm{~g} / \mathrm{L}$, which was three times higher than that in the CPAM1-EMCB reaction. The difference in catalytic ability between the PEI-EMCB and CPAM-EMCB might be caused by the different amount of enzyme fixed on the carriers. Moreover, the difference in properties between PEI and CPAM might also influence the activity of the immobilized enzyme. (Bolivar et al. 2009; Mateo et al. 2000). It can be found in Fig. 2 that the GA concentration in PEIEMCB catalyzed reaction became higher than free enzyme after about $40 \mathrm{~min}$, which is 
possibly because that the stability of the enzyme was improved and more enzyme molecules remained active after being immobilized in the reaction (Zaak et al. 2017).

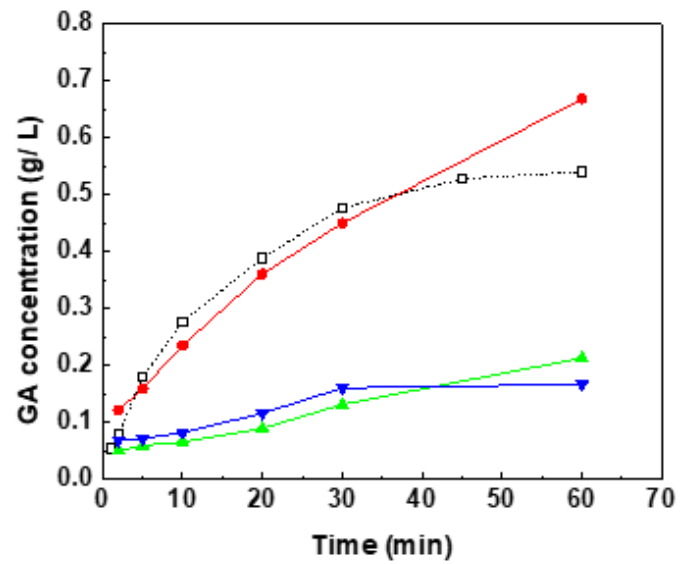

Fig. 2. Change of galacturonic acid (GA) during the enzyme-catalyzed reaction for free enzyme $(\square), \operatorname{PEI}-\operatorname{EMCB}(\bullet)$, CPAM1- EMCB $(\boldsymbol{\Delta})$, and CPAM3-EMCB $(\boldsymbol{\nabla})$
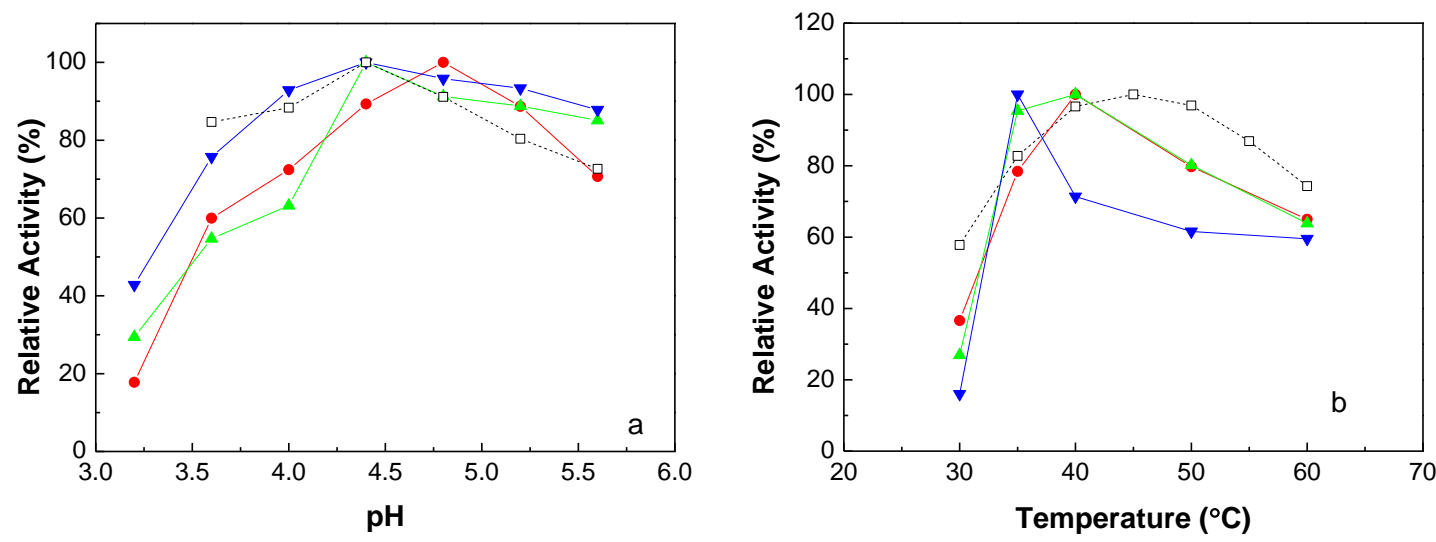

Fig. 3. Effect of $\mathrm{pH}$ (a) and temperature (b) on enzymatic activity for free enzyme ( $\square$ ), PEI-EMCB $(\bullet)$, CPAM1- EMCB $(\boldsymbol{\Delta})$, and CPAM3-EMCB $(\boldsymbol{\nabla})$. Relative activity was expressed as the ratio of the activity to the maximum activity for each enzyme.

The plot of activity versus $\mathrm{pH}$ value is presented in Fig. 3a. The shape of the $\mathrm{pH}$ profile was influenced by the polymer utilized. After immobilization on regenerated cellulose beads, PEI-EMCB had its optimum $\mathrm{pH}$ increase of 0.4 , while the optimal $\mathrm{pH}$ for CPAM-immobilized enzymes stayed the same with the free enzyme (4.4). Moreover, it was found that the stability of pectinase on the right side was enhanced after immobilization, probably as a consequence of the interactions between the enzyme and the polymers. The cationic polyelectrolytes might combine with the enzyme through multiple points and maintain the structure of the enzyme to prevent inactivation (Bolivar et al. 2009; Zaak et al. 2017). However, the bound enzyme became more sensitive to $\mathrm{pH}$ changes when the $\mathrm{pH}$ decreased from 4.5, which can be possibly ascribed to the $\mathrm{pH}$ variation in microenvironment from the bulk caused by the charge on the carrier (Guedidi et al. 2010). Similar reports were also reported in other studies (Santos et al. 2014). Among all three types, CPAM3-EMCB possessed the highest tolerance against $\mathrm{pH}$ variation, and $90 \%$ of its activity was preserved over a wide range. This might have been due to the high 
molecular weight of CPAM3, which facilitates multipoint interaction with enzyme molecules for stable conformation.

Figure $3 \mathrm{~b}$ depicts the temperature profile of the enzymes. It was revealed that the shape of the temperature profile of the immobilized enzyme on magnetic regenerated cellulose beads was quite different from the free enzyme. The optimum temperature for the bound enzyme decreased in comparison with its free counterpart $\left(45^{\circ} \mathrm{C}\right)$. However, the fixed enzymes were more sensitive to temperature change when temperature rose from 40 to $60{ }^{\circ} \mathrm{C}$; this is likely attributable to different regimes the polyelectrolytes experienced at varying temperatures (Jesudason et al. 2009).

Both soluble and fixed enzymes were found to follow Michaelis-Menten kinetics over the experimental pectin concentration range, and the results are listed in Table 2. After immobilized through electrolytes, a decrease of more than an order of magnitude for the maximum reaction velocity $\left(V_{\mathrm{m}}\right)$ was observed for all the bound enzymes. This might be the consequence of increased accessibility limitation of substrate molecules to reach the active sites of the enzyme (de Oliveira et al. 2018). The apparent $K_{\mathrm{m}}$ value for the fixed enzymes decreased more than half compared to the soluble form, indicating higher affinity for substrate. This phenomenon might be explained by that substrate becoming gathered around the carrier so that the local substrate concentration increased. Moreover, the positive charge on the matrix might be favourable for the adsorption of the substrate. Similar results were also observed in other work (de Oliveira et al. 2018; Ferreira et al. 2018).

Table 2. Apparent Kinetic Parameters for Free and Immobilized Enzymes

\begin{tabular}{|c|c|c|}
\hline & $K_{\mathrm{m}}$ & $V_{\mathrm{m}}$ \\
\hline Free enzyme & 9.77 & 0.75 \\
\hline PEI-EMCB & 2.34 & 0.046 \\
\hline CPAM1- EMCB & 3.93 & 0.035 \\
\hline CPAM3- EMCB & 3.75 & 0.039 \\
\hline
\end{tabular}

\section{Storage Stability and Reusability of Immobilized Enzymes}

The storage stability of the obtained immobilized enzyme was investigated. The catalytic activity of $0.25 \%(\mathrm{v} / \mathrm{v})$ free enzyme dropped nearly half after being stored for one day, and the turbidity of the enzyme solution increased. As illustrated in Fig. 4a, the activity of the bound enzyme decreased during storage. The activity of the enzyme declined to $67 \%$, $53 \%$, and $58 \%$ after 7 days for PEI-EMCB, CPAM1-EMCB, and CPAM3-EMCB, respectively. Compared with enzyme immobilized using CPAM, PEI-immobilized enzyme retained higher activity during storage. It has been reported that the stability of enzymes was improved due to the physical intermolecular crosslinking by PEI (Peirce et al. 2016; Zaak et al. 2017). In contrast, the performance of PEI-EMCB for repeated utilization was the worst among the three fixed enzymes, as described in Fig. 4b. The residual activity for PEI-EMCB dropped $36 \%$ after the first cycle while approximately $10 \%$ of the activity was lost for CPAM-immobilized enzymes. After 7 cycles of reaction, PEI-EMCB, CPAM1EMCB, and CPAM3-EMCB maintained $32 \%, 51 \%$, and $45 \%$ of the original activity, respectively. However, the retained absolute activity of PEI-EMCB after 7 cycles was still remarkably higher than CPAM-EMCB in light of its high original activity. The reusability of the immobilized enzyme on magnetic cellulose beads without using electrolyte was also investigated for comparison and less than $10 \%$ of the starting activity was retained when 
the enzyme was recycled for 7 times. The physical morphology of the cellulose beads remained unchanged, and no damage to cellulose beads was found after seven cycles, indicating that the cellulose beads maintained good mechanical strength when utilized repeatedly as a carrier. In addition, the immobilized enzyme could be conveniently collected after reaction using an external magnetic field as presented in Fig. 4d. The immobilized enzyme obtained might be potentially used in industry due simple preparation and convenience. The magnetic properties of the regenerated cellulose beads were characterized. Figure $4 \mathrm{c}$ shows the magnetic properties of the obtained magnetic regenerated cellulose beads. The small hysteresis loop and low coercivity indicated that the microspheres were nearly superparamagnetic (Luo et al. 2015).
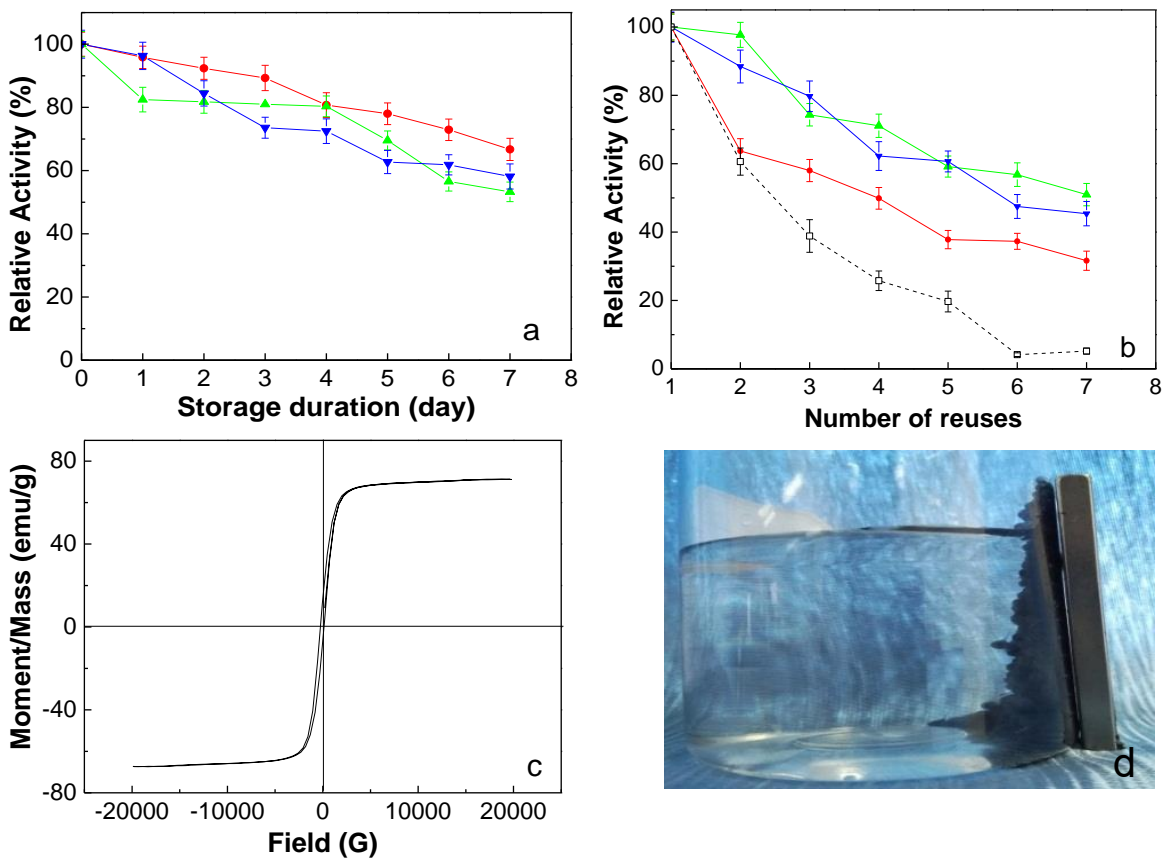

Fig. 4. Storage stability (a) and reusability (b) of PEI-EMCB (•), CPAM1-EMCB ( $\mathbf{\Delta})$, CPAM3EMCB $(\boldsymbol{\nabla})$ and enzyme immobilized on magnetic cellulose beads without using electrolyte $(\square)$; the magnetic hysteresis curve of magnetic cellulose beads (c) and beads aggregation by magnet (d). Relative activity was defined as the percentage of the activity to the initial activity for each enzyme.

\section{CONCLUSIONS}

1. Magnetic regenerated cellulose beads with porous structure were prepared and utilized as an enzyme carrier through a simple method. Two kinds of polyelectrolytes, PEI and CPAM, were employed for enzyme fixation via ionic adsorption. PEI-immobilized enzyme showed the highest catalytic activity $(2711 \mathrm{U} / \mathrm{g})$ and a similar reaction course to the solution enzyme, while the catalytic capability of the CPAM-immobilized enzymes was much lower.

2. PEI-EMCB reached its maximal activity at $\mathrm{pH} 4.8$ while the optimal $\mathrm{pH}$ for CPAMEMCB was the same as the free form (4.4). Moreover, CPAM3-EMCB was the most 
insusceptible to $\mathrm{pH}$ change. This is possibly ascribed to the high molecular weight of CPAM3. After immobilization, the optimum temperature for the enzyme declined.

3. PEI-EMCB exhibited the best storage stability with $67 \%$ of the initial activity retained after 7 days and CPAM-EMCBs showed better reusability stability. Moreover, the magnetic properties of the regenerated cellulose beads provided convenience for the immobilized enzyme to be used and recycled using an external magnetic field.

\section{ACKNOWLEDGMENTS}

The authors are grateful to the Innovation fund for young teachers of Tianjin University of Science and Technology (2016LG19) for their financial support.

\section{REFERENCES CITED}

Bognitzki, M., Czado, W., Frese, T., Schaper, A., Hellwig, M., Steinhart, M., Greiner, A., and Wendorff, J. H. (2001). "Nanostructured fibers via electrospinning," Advanced Materials 13(1), 70-72.

Bolivar, J. M., Eisl, I., and Nidetzky, B. (2016). "Advanced characterization of immobilized enzymes as heterogeneous biocatalysts," Catalysis Today 259, 66-80. DOI: 10.1016/j.cattod.2015.05.004

Bolivar, J. M., Rocha-Martin, J., Mateo, C., Cava, F., Berenguer, J., Fernandez-Lafuente, R., and Guisan, J. M. (2009). "Coating of soluble and immobilized enzymes with ionic polymers: Full stabilization of the quaternary structure of multimeric enzymes," Biomacromolecules, 10(4), 742-747. DOI: 10.1021/bm801162e

Choi, J., Han, S., and Kim, H. (2015). "Industrial applications of enzyme biocatalysis: Current status and future aspects," Biotechnology Advances 33, 1443-1454. DOI: 10.1016/j.biotechadv.2015.02.014

Coombs OBrien, J., Torrente-Murciano, L., Mattia, D., and Scott, J. L. (2017). "Continuous production of cellulose microbeads via membrane emulsification," ACS Sustainable Chemistry \& Engineering 5(7), 5931-5939. DOI: 10.1021/acssuschemeng.7b00662

de Oliveira, R. L., Dias, J. L., Da Silva, O. S., and Porto, T. S. (2018). "Immobilization of pectinase from Aspergillus aculeatus in alginate beads and clarification of apple and umbu juices in a packed bed reactor," Food and Bioproducts Processing 109, 9-18. DOI: 10.1016/j.fbp.2018.02.005

Fernandez-Lopez, L., Pedrero, S. G., Lopez-Carrobles, N., Gorines, B. C., Virgen-Ortíz, J. J., and Fernandez-Lafuente, R. (2017). "Effect of protein load on stability of immobilized enzymes," Enzyme and Microbial Technology 98, 18-25. DOI: 10.1016/j.enzmictec.2016.12.002

Ferreira, M. M., Santiago, F. L. B., Silva, N. A. G. D., Luiz, J. H. H., FernandézLafuente, R., Mendes, A. A., and Hirata, D. B. (2018). "Different strategies to immobilize lipase from Geotrichum candidum: Kinetic and thermodynamic studies," Process Biochemistry 67, 55-63. DOI: 10.1016/j.procbio.2018.01.028

Fuente, E., Blanco, A., Negro, C., Pelach, M. A., Mutje, P., and Tijero, J. (2005). "Study of filler flocculation mechanisms and floc properties induced by polyethylenimine," 
Industrial \& Engineering Chemistry Research 44(15), 5616-5621

Gericke, M., Trygg, J., and Fardim, P. (2013). "Functional cellulose beads: Preparation, characterization, and applications," Chemical Reviews 113, 4812-4836

Guedidi, S., Yurekli, Y., Deratani, A., Déjardin, P., Innocent, C., Altinkaya, S. A., Roudesli, S., and Yemenicioglu, A. (2010). "Effect of enzyme location on activity and stability of trypsin and urease immobilized on porous membranes by using layerby-layer self-assembly of polyelectrolyte," Journal of Membrane Science 365, 59-67.

Guzmán, E., Mateos-Maroto, A., Ruano, M., Ortega, F., and Rubio, R. G. (2017). "Layerby-layer polyelectrolyte assemblies for encapsulation and release of active compounds," Advances in Colloid and Interface Science 249, 290-307. DOI: 10.1016/j.cis.2017.04.009

Jesudason, C. G., Lyubartsev, A. P., and Laaksonen, A. (2009). "Conformational characteristics of single flexible polyelectrolyte chain," The European Physical Journal E 30(4). DOI: 10.1140/epje/i2009-10532-5

Liu, D., Chen, J., and Shi, Y. (2018). "Advances on methods and easy separated support materials for enzymes immobilization," TrAC Trends in Analytical Chemistry 102, 332-342. DOI: 10.1016/j.trac.2018.03.011

Luo, X., Zeng, J., Liu, S., and Zhang, L. (2015). "An effective and recyclable adsorbent for the removal of heavy metal ions from aqueous system: Magnetic chitosan/cellulose microspheres," Bioresource Technology 194, 403-406.

Mateo, C., Abian, O., Fernandez Lafuente, R., and Guisan, J. M. (2000). "Reversible enzyme immobilization via a very strong and nondistorting ionic adsorption on support - polyethylenimine composites," Biotechnology and Bioengineering 68(1), 98-105.

Mateo, C., Fernandes, B., van Rantwijk, F., Stolz, A., and Sheldon, R. A. (2006). "Stabilisation of oxygen-labile nitrilases via co-aggregation with poly(ethyleneimine)," Journal of Molecular Catalysis B: Enzymatic 38(3-6), 154-157. DOI: 10.1016/j.molcatb.2005.12.007

Peirce, S., Tacias-Pascacio, V., Russo, M., Marzocchella, A., Virgen-Ortíz, J., and Fernandez-Lafuente, R. (2016). "Stabilization of Candida antarctica lipase B (CALB) immobilized on octyl agarose by treatment with polyethyleneimine (PEI)," Molecules 21(6), 751. DOI: 10.3390/molecules21060751

Rehman, H. U., Aman, A., Nawaz, M. A., Karim, A., Ghani, M., Baloch, A. H., and Qader, S. A. U. (2016). "Immobilization of pectin depolymerising polygalacturonase using different polymers," International Journal of Biological Macromolecules 82, 127-133. DOI: 10.1016/j.ijbiomac.2015.10.012

Santos, J. C. S. D., Garcia-Galan, C., Rodrigues, R. C., Ana, H. B. D. S., Gonçalves, L. R. B., and Fernandez-Lafuente, R. (2014). "Improving the catalytic properties of immobilized lecitase via physical coating with ionic polymers," Enzyme \& Microbial Technology 60(1), 1-8

Sheldon, R. A., and van Pelt, S. (2013). "Enzyme immobilisation in biocatalysis: Why, what and how," Chem. Soc. Rev. 42(15), 6223-6235.10.1039/C3CS60075K

Wang, Q., Liu, S., Yang, G., Chen, J., and Ni, Y. (2015). "Cationic polyacrylamide enhancing cellulase treatment efficiency of hardwood kraft-based dissolving pulp," Bioresource Technology 183, 42-46. DOI: 10.1016/j.biortech.2015.02.011

Wang, S., Lu, A., and Zhang, L. (2016). "Recent advances in regenerated cellulose materials," Progress in Polymer Science 53, 169-206. DOI:

10.1016/j.progpolymsci.2015.07.003 
Wang, Y., Chen, K., Mo, L., Li, J., and Xu, J. (2014). "Optimization of coagulation flocculation process for papermaking-reconstituted tobacco slice wastewater treatment using response surface methodology," Journal of Industrial and Engineering Chemistry 20(2), 391-396. DOI: 10.1016/j.jiec.2013.04.033

Wu, R., Huang, P., and He, B. (2016). "Preparation and characterization of regenerated cellulose microspheres and the adsorption of pectinase," BioResources 11(2), 41464158. DOI: 10.15376/biores.11.2.4146-4158

Zaak, H., Fernandez-Lopez, L., Otero, C., Sassi, M., and Fernandez-Lafuente, R. (2017). "Improved stability of immobilized lipases via modification with polyethylenimine and glutaraldehyde," Enzyme and Microbial Technology 106, 67-74. DOI: 10.1016/j.enzmictec.2017.07.001

Article submitted: November 18, 2019; Peer review completed: January 15, 2020;

Revised version received and accepted: March 18, 2020; Published: March 19, 2020.

DOI: 10.15376/biores.15.2.3190-3200 